\title{
Capítulo

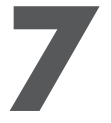

\section{Repartição de receita do ICMS em Pernambuco: unidades de conservação e resíduos sólidos}

No Estado de Pernambuco, a transferência constitucional da receita do ICMS aos municípios é realizada no segundo dia útil de cada semana, com base nos créditos verificados nas contas de arrecadação na semana imediatamente anterior. $\mathrm{Na}$ realidade, a quantia transferida corresponde ao ICMS Líquido, equivalente à quota constitucional a que os municípios têm direito, menos $20 \%$ do valor, que compõe o Fundo de Manutenção e Desenvolvimento da Educação Básica e de Valorização dos Profissionais da Educação (Fundeb). Na Figura 7.1 são demonstrados os valores do ICMS Líquido total, em bilhões de reais, transferidos aos municípios pernambucanos, entre 2010 e 2016, ou seja, os $25 \%$ da parcela constitucional descontada a quota do Fundeb.

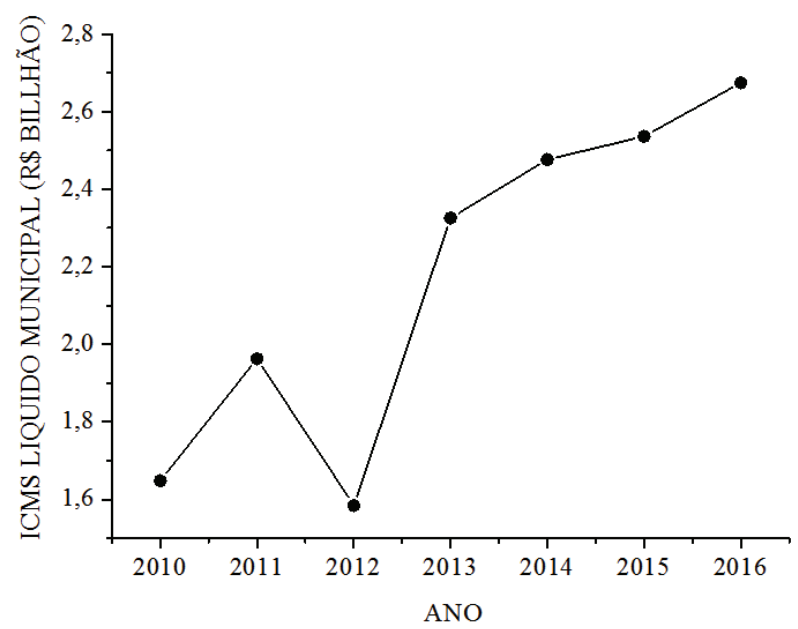

Figura 7.1 ICMS Líquido (RS/bihões) transferido aos municípios de Pernambuco (2010-2016).

Fonte: baseado em dados da Secretaria da Fazenda de Pernambuco.'

1 Dados disponíveis em: <http://www.sefaz.pe.gov.br/RPM/Scripts/TransfConstitucionalCons.asp $>$. 
Na Figura 7.1 chama atenção o crescimento da receita do ICMS Líquido em Pernambuco entre 2015 e 2016, na contramão dos indicadores de arrecadação tributária no âmbito federal, conforme publicação do Jornal Folha de S.Paulo, de 27 de janeiro de 2017, intitulada "Com crise, arrecadação em 2016 foi a pior desde 2010":

Com a crise econômica a arrecadação federal somou $\mathrm{R}$ \$ 1,289 trilhão no ano passado, o pior resultado desde 2010, divulgou nesta sexta (27) a Receita Federal. Na comparação com 2015, a queda real (retirado o efeito da inflação) foi de $2,97 \%$. Foi o terceiro ano seguido de queda na arrecadação. No caso somente das receitas administradas pela Receita Federal, que somaram R \$1,265 trilhão em 2016, a queda foi de 2,38\% na comparação com 2015. Se o resultado não levar em conta a receita extra da multa e imposto da chamada repatriação (a regularização de recursos ilegais no exterior), a arrecadação da Receita totalizaria $\mathrm{R} \$ 1,218$ trilhão, uma redução ainda maior, de $5,95 \%$ ante 2015 . O comportamento da arrecadação reflete a recessão da economia brasileira.

Mas em Pernambuco, no que se refere ao ICMS, no final de 2015 foi aprovado o aumento das alíquotas incidentes nos fatos geradores do tributo, consolidadas na Lei Estadual $n^{\circ} 15.730$, de 17 de março de 2016, que dispõe sobre o ICMS no Estado. Este fato é retratado na publicação de 30 de setembro de 2015 no sítio G1, intitulada "Aumento de impostos é aprovado em Pernambuco e vale a partir de 2016”, o que justifica o crescimento do ICMS Líquido transferido aos municípios pernambucanos:

Com algumas emendas alterando o texto original, o texto aprovado na Assembleia Legislativa de Pernambuco (Alepe), região central do Recife, segue agora para ser sancionado pelo governador Paulo Câmara. [...] Nas operações com motocicletas, a alíquota do ICMS sobe de $12 \%$ para $18 \%$. A proposta do governo também altera as alíquotas do ICMS incidentes sobre a gasolina e o álcool. A alíquota da gasolina sobe de $27 \%$ para $29 \%$, enquanto a do álcool cai de $25 \%$ para $23 \%$. Sobre serviços de telecomunicações, o ICMS sobe de $28 \%$ para $30 \%$, e de TV por assinatura, de $10 \%$ para $15 \%$. O aumento nessa alíquota sobre os serviços de telecomunicações será destinado ao Fundo de Combate à Pobreza. Para os produtos que não contam com legislação específica, a alíquota do ICMS sobe de $17 \%$ para $18 \%$.

As quantias do ICMS Líquido, em milhões de reais, transferidas aos municípios com os maiores IDHM nas Regiões de Desenvolvimento de Pernambuco, no 
período de 2010 a 2016, são apresentadas na Figura 7.2. Verifica-se, assim como na Figura 7.1, uma descontinuidade em 2012, que indica uma diminuição na arrecadação do ICMS no Estado. Tal fato está relacionado à queda da atividade econômica neste ano, bem ilustrada na publicação de 4 de dezembro de 2012 da Revista Exame, intitulada Por que a economia brasileira decepcionou em 2012? (SOBRAL, 2012):

O fraco crescimento do produto interno bruto (PIB) do Brasil foi a grande decepção do ano para o mercado, na opinião de Mario Felisberto, diretor de investimentos da HSBC Global Asset Management. "Mercado, governo, quase ninguém antecipava o que aconteceria em 2012", [...]. "A projeção geral era de um crescimento entre 3\% e 4\%".

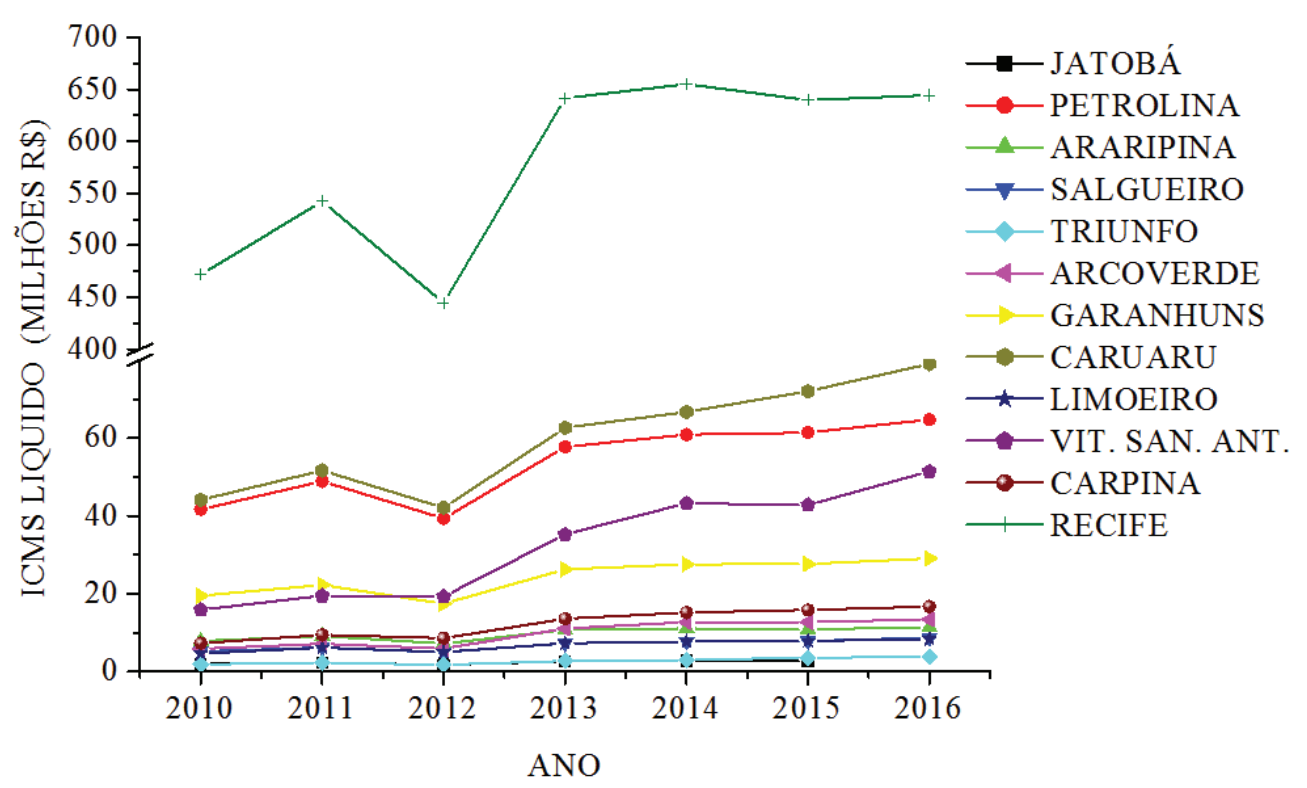

Figura 7.2 ICMS Líquido (RS/milhöes) transferido aos municípios com os maiores IDHM nas Regiões de Desenvolvimento de Pernambuco (2010-2016).

Fonte: baseado em dados da Secretaria da Fazenda de Pernambuco.

$\mathrm{Na}$ Figura 7.2, constata-se uma centralização no repasse constitucional da receita do ICMS para a capital pernambucana, que em 2016 recebeu 24,1\% do produto da arrecadação do ICMS a que têm direito os municípios no Estado, com o montante praticamente constante ao longo de 2013 a 2016. Mas como ocorreu um aumento no ICMS arrecadado (Figura 7.1), as informações indicam uma redistribuição do tributo entre os demais municípios em Pernambuco, fato corroborado pela redução de 3,46\% no IPM-ICMS do Recife entre 2013 e 2016 (Figura 7.3). 
No que tange ao IPM-ICMS, verifica-se, na Figura 7.3, que dos municípios em análise, entre 2015 e 2016, somente Salgueiro, Caruaru, Limoeiro e Vitória de Santo Antão tiveram acréscimo no referido índice, mas sem correlação direta com a quantia transferida do ICMS arrecadado, pois esta depende dos fatos geradores, da base de cálculo e das alíquotas deste tributo, ou seja, da atividade econômica no Estado. Essa observação demonstra a importância de os municípios pernambucanos maximizarem os índices relativos aos critérios previstos na Lei do ICMS Socioambiental, para minimizarem as perdas na receita tributária devido a diminuição da arrecadação do ICMS em períodos de crises econômicas.

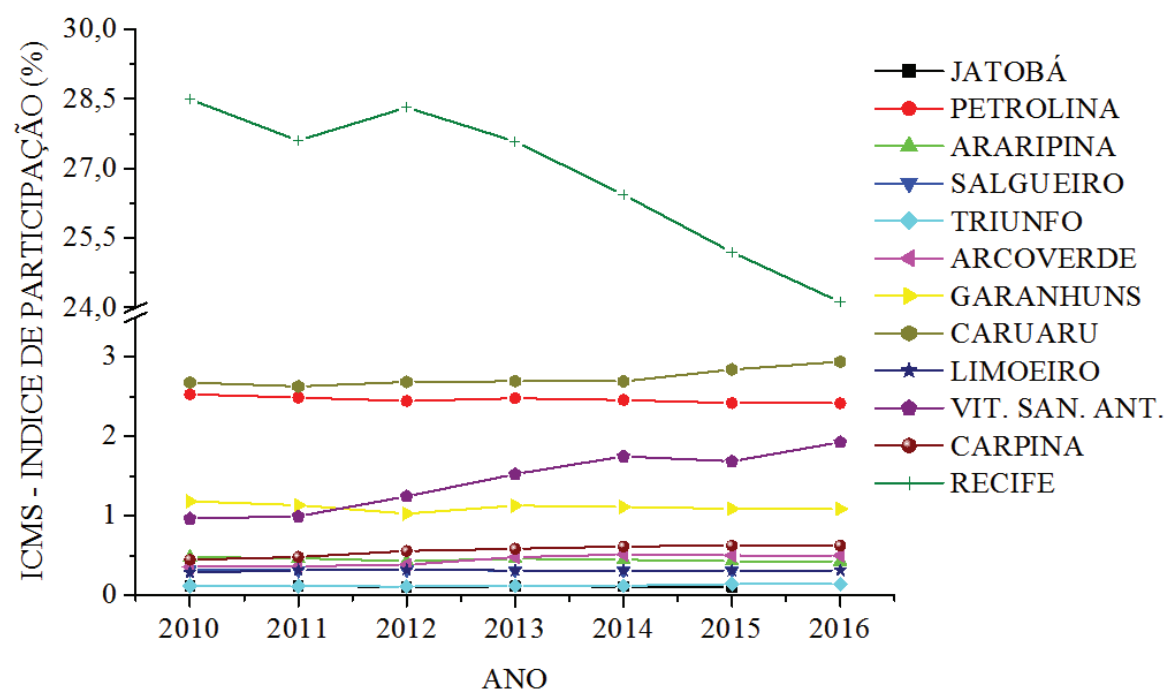

Figura 7.3 IPM-ICMS dos municípios com os maiores IDHM nas Regiões de Desenvolvimento de Pernambuco (2010-2016).

Fonte: baseado em dados da Secretaria da Fazenda de Pernambuco.

Com relação à Lei do ICMS Socioambiental de Pernambuco, não foi possível avaliar a influência individualizada dos critérios socioambientais nos valores dos Índices de Participação dos Municípios na receita do ICMS, porque as informações fornecidas pela Secretaria da Fazenda de Pernambuco fazem apenas menção ao ICMS arrecadado e ao IPM-ICMS global. No entanto, as quantias transferidas da receita do ICMS Líquido aos municípios em 2015, relacionadas com os critérios Unidades de Conservação e Resíduos Sólidos, são encontradas no sítio do Tribunal de Contas do Estado de Pernambuco, o que permitiu realizar a análise da influência desses critérios no repasse constitucional do ICMS arrecadado aos municípios com os maiores IDHM nas Regiões de Desenvolvimento do Estado.

É importante relembrar que, nos exercícios de 2010 a 2017, os critérios ambientais utilizados no cálculo IPM-ICMS foram: Unidades de Conservação e 
Resíduos Sólidos (Sistemas de Tratamento ou de Destinação Final de Resíduos Sólidos), nos termos artigo $2^{\circ}$, inciso II, alínea "d" da Lei do ICMS Socioambiental de Pernambuco, sem abranger os critérios Áreas de Proteção de Mananciais Preservados de Rios e Usinas de Reciclagem de Lixo.

Em 2015, a quantia do ICMS Líquido, relacionada com a componente ambiental (Unidades de Conservação e Resíduos Sólidos), transferida aos municípios beneficiados, foi de R $\$ 75.688 .805,12$. Este valor corresponde a $0,75 \%$ da receita do ICMS arrecadado, abatido os $20 \%$ para compor o Fundeb, dos quais 0,25\% está relacionado ao critério Unidades de Conservação e 0,50\% ao critério Resíduos Sólidos, representando, respectivamente, R\$ 25.229.601,71 e R\$ 50.459.203,41.

$\mathrm{Na}$ Figura 7.4 são demonstradas, em reais (R\$), as quantias transferidas do ICMS Líquido aos municípios com os maiores IDHM nas Regiões de Desenvolvimento de Pernambuco relacionadas com o critério Resíduos Sólidos (RS) nos doze meses de 2015.

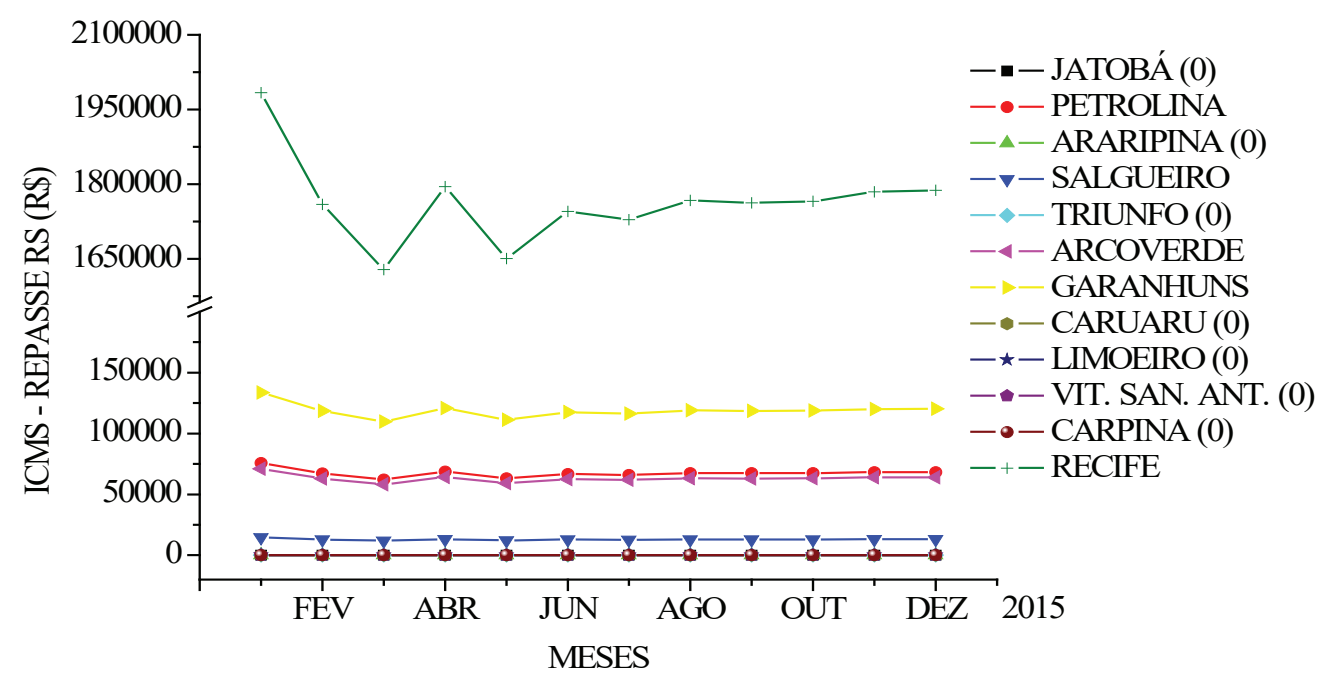

Figura 7.4 Valores dos repasses do ICMS Líquido relacionados ao critério Residuos Sólidos (RS) - Aterro Sanitário e Unidade de Compostagem - para os municíios com os maiores IDHM nas Regiōes de Desenvolvimento de Pernambuco (2015).

Fonte: baseado em dados do Tribunal de Contas do Estado de Pernambuco (Anexo D).

$\mathrm{Na}$ apresentação da componente ambiental da Lei do ICMS Socioambiental, nos itens 6.1.1.1 e 6.1.1.2, demonstrou-se, na Figura 6.6, que em 2015 Jatobá, Araripina, Triunfo, Limoeiro, Caruaru, Vitória de Santo Antão e Carpina não pontuaram no critério Resíduos Sólidos, de modo que não receberam parte do produto da arrecadação do ICMS com relação a esse componente ambiental, fato também evidenciado na Figura 7.4. 
A Lei do ICMS Socioambiental de Pernambuco, no que se refere ao critério Resíduos Sólidos, é regulada pelo Decreto Estadual n 23.473/2001, conforme previsão do art. $7^{\circ}$ do Decreto Estadual n ${ }^{\circ} 33.797 / 2009$. O artigo 10 do Decreto Estadual $n^{\circ} 23.473 / 2001$, modificado pelo Decreto $n^{\circ} 26.030 / 2003$, prevê que a receita do ICMS deve ser distribuída proporcionalmente ao produto resultante da multiplicação do número de habitantes de cada Município pelo número de pontos obtidos nos termos do Anexo Único do texto legal, apresentado na Tabela 7.1.

Tabela 7.1 Pontuação para habilitação dos municípios em relação ao critério dos Resíduos Sólidos previstos no Decreto Estadual no 23.473/2001 que regulamenta a Lei do ICMS Socioambiental de Pernambuco

\section{Unidade de compostagem}

\begin{tabular}{|l|l|}
\hline \multicolumn{1}{|c|}{ Etapa } & \multicolumn{1}{c|}{ Pontuação } \\
\hline a) Projeto & \\
\hline Licença prévia & 2,0 \\
\hline Licença de instalacã̃o & 3,0 \\
\hline b) implantação & \\
\hline Licença de operaçãa & 5,0 \\
\hline c) Operação regular & 10,0 \\
\hline Pontuação máxima obtida por unidade de compostagem & 20,0 \\
\hline
\end{tabular}

\section{Aterro sanitário}

\begin{tabular}{|c|c|}
\hline Etapa & Pontuação \\
\hline \multicolumn{2}{|l|}{ a) Projeto } \\
\hline Licença prévia & 3,0 \\
\hline Licença de instalacãão & 7,0 \\
\hline \multicolumn{2}{|l|}{ b) implantação } \\
\hline Licença de operação & 10,0 \\
\hline c) Operação regular* & 40,0 \\
\hline d) Desativação do vazadouro (lixão) & 20,0 \\
\hline Pontuação máxima obtida por aterro sanitário & 80,0 \\
\hline
\end{tabular}

Fonte: Decreto Estadual n²3.473, de 10 de agosto de 2001.

Em conformidade com o dispositivo mencionado, para o cálculo do IPM-ICMS, relacionado ao critério Resíduos Sólidos, deve-se levar em consideração a população urbana do município habilitado, o que justifica o repasse, em 2015, de 
$41,9 \%$ da quantia referente a esse critério para a capital pernambucana, correspondendo a R $\$ 21.158 .642,42$.

É importante destacar que o art. $9^{\circ}$ do Decreto Estadual n ${ }^{\circ} 23.473 / 2001$ prevê que:

Serão considerados não habilitados, independentemente do atendimento aos critérios previstos nos arts. $6^{\circ}$ e $7^{\circ}$ e seus parágrafos do presente Decreto, os Municípios nos quais a CPRH constatar, a qualquer momento, uma ou mais das seguintes situações:

I - criança catando lixo em aterros ou em vazadouros (lixões);

II - resíduos sólidos depositados irregularmente a menos de 200 (duzentos) metros de mananciais;

III - resíduos tóxicos, inflamáveis, corrosivos ou patogênicos, relacionados na classe I, da Norma Brasileira - NBR n ${ }^{\circ} 10.004$, da Associação Brasileira de Normas Técnicas - ABNT, depositados no solo sem tratamento; IV - catadores de lixo residindo nas áreas de disposição final dos resíduos pelos Municípios;

$\mathrm{V}$ - não atendimento ao disposto no $\mathbb{S} 4^{\circ}$, do art. $8^{\circ}$ deste Decreto; e VI - existência de mais de $20 \%$ (vinte por cento) dos resíduos produzidos, no Município, sem tratamento em usina de compostagem ou depositados em aterros sanitários.

Essas restrições justificam o fato de os municípios Salgueiro e Petrolina não serem beneficiados na partilha do produto da arrecadação do ICMS com relação ao critério Resíduos Sólidos em 2015, uma vez que ambos apresentaram a pontuação 20, conforme a Portaria Sefaz-PE no 169/2014.

Na Portaria Sefaz-PE no 269/2015 (Anexo C) encontram-se as pontuações do critério Resíduos Sólidos utilizadas no cálculo do IPM-ICMS para o exercício 2016. Os dados demonstram que neste ano $29,4 \%$ dos municípios pernambucanos pontuaram no critério em análise, mas apenas 18,5\% foram beneficiados na repartição da receita do ICMS no Estado. Segundo Silva Jr. et al. (2010), em 2008, somente foram agraciados dezenove entes municipais, o que corresponde a 10,3\%, de modo que em 8 anos houve um incremento de $8,2 \%$ na quantidade dos entes contemplados com o produto da arrecadação do ICMS com relação ao critério Resíduos Sólidos.

A problemática do tratamento e disposição dos resíduos sólidos em Pernambuco é bem retratada no texto Tribunal de Contas divulga diagnóstico sobre destinação do lixo em Pernambuco (TCE, 2014):

O levantamento mostra que a maior parte $(82,6 \%)$ dos 184 municípios pernambucanos ainda não deposita seus resíduos sólidos em aterros sanitários. 
Em 129 municípios (70,1\%) os dejetos são descartados em lixões. Apenas 32 cidades $(17,4 \%)$ utilizam locais adequados para o serviço, enquanto que 23 municípios $(12,5 \%)$ depositam o seu lixo nos chamados "aterros controlados”, que seria uma situação intermediária, mas ainda inadequada. Pernambuco dispõe apenas de 9 aterros sanitários licenciados, um número bem abaixo do considerado ideal pelo Plano Estadual de Resíduos Sólidos para atender às necessidades da população, que seria de 54 aterros. (grifo nosso)

$\mathrm{Na}$ literatura especializada há trabalhos relevantes que abordam a temática em análise, como os de Silva Jr. e Sobral (2014); Silva Jr. e Branco (2012); Silva Jr. et al. (2010) e Fernandes (2005), cujos estudos destacam a importância da Lei do ICMS Socioambiental de Pernambuco para a tutela do meio ambiente. Entretanto, de modo geral, relatam a ineficácia da componente ambiental na consolidação de Políticas de Resíduos Sólidos no âmbito local. Essa situação justifica-se pela fórmula utilizada no Decreto Estadual $n^{\circ}$ 23.473/2001, que beneficia os municípios mais populosos na repartição da receita do ICMS. Na realidade, a implantação dessas políticas deve ser impulsionada com a aplicação da Lei Federal no 12.305/2010 (PNRS), que exige a extinção dos lixões e a aprovação de Planos Municipais de Gestão Integrada de Resíduos Sólidos para que as cidades tenham acesso a recursos da União.

As quantias, em reais, do ICMS Líquido transferidas aos municípios com os maiores IDHM nas Regiões de Desenvolvimento de Pernambuco, relacionadas ao critério Unidades de Conservação (UC), nos doze meses de 2015, são apresentadas na Figura 7.5. Os entes Jatobá, Petrolina, Araripina, Salgueiro, Triunfo, Arcoverde, Limoeiro e Carpina não pontuaram neste componente ambiental, de maneira que não foram beneficiados na repartição do produto da arrecadação do ICMS com relação ao critério UC no referido ano.

A Lei do ICMS Socioambiental, no que diz respeito ao critério Unidades de Conservação, é regulada pelos Decretos Estaduais n ${ }^{\circ} 23.473 / 2001, n^{\circ} 25.574 / 2003$ e ${ }^{\circ} 33.797 / 2009$. O artigo $2^{\circ}$ do Decreto Estadual no $23.473 / 2001$ determina:

Art. $2^{\circ}$. Para o cálculo do índice de participação de cada município, no que se refere às unidades de conservação, serão considerados os dados: I - área de conservação do município: área igual ao somatório de todas as àreas das unidades de conservação constantes no diploma legal de criação, existentes em seu território;

II - área de conservação do Estado: área igual ao somatório de todas as àreas de conservação dos municípios;

III - índice de conservação do município: relação entre a sua área de conservação e a área de conservação do Estado. 
$\mathbb{S} 1^{\circ}$. Não serão consideradas as áreas dos municípios que não atenderem aos critérios de inclusão definidos neste Decreto, assim como deverá ser observado o limite de $10 \%$ (dez por cento) para a participação relativa de qualquer município.

$\mathbb{S} 2^{\circ}$. Sempre que a participação relativa de qualquer município ultrapassar o limite de $10 \%$ (dez por cento) da área de conservação total do Estado, esse excedente será distribuído igualmente entre todos os municípios que possuírem unidades de conservação. (grifo nosso)

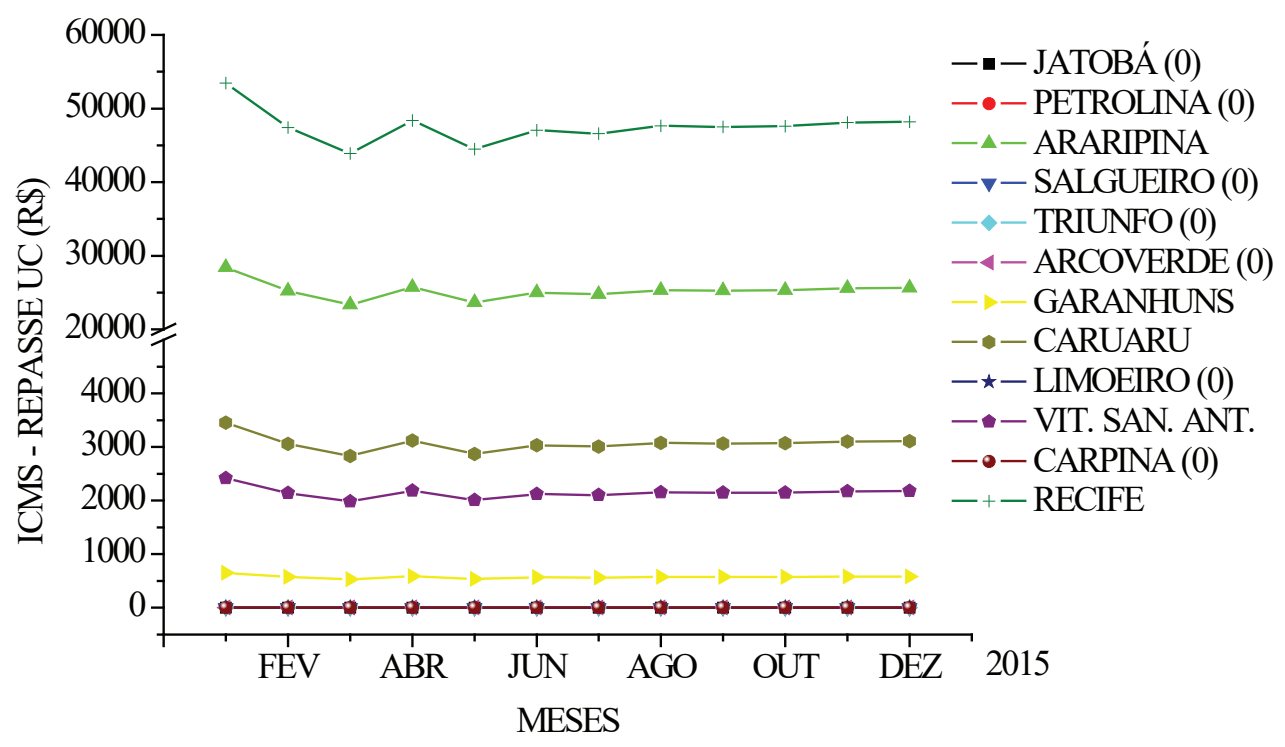

Figura 7.5 Valores dos repasses do produto da arrecadação do ICMS, relacionados ao critério Unidades de Conservação, para os municipios com os maiores IDHM nas Regiōes de Desenvolvimento de Pernambuco (2015). Fonte: baseado em dados do Tribunal de Contas do Estado de Pernambuco (Anexo D).

$\mathrm{O}$ artigo $2^{\circ}, \mathbb{S} 1^{\circ}$ do Decreto Estadual n ${ }^{\circ}$ 23.473/2001 fixa o limite de $10 \%$ para a participação relativa de qualquer Município na repartição da receita do ICMS com relação ao critério UC, mas é no art. $3^{\circ}$ do Decreto Estadual $n^{\circ}$ 25.574/2003, que são apresentadas as variáveis qualitativas e quantitativas para o cálculo do índice deste critério ambiental.

Art. $3^{\circ}$ No cálculo do ICMS socioambiental referente às unidades de conservação, são consideradas variáveis de caráter quantitativo e qualitativo: $\mathbb{S} 1^{\circ}$ São variáveis de caráter quantitativo, a área da unidade de conservação, a área do Município onde a unidade de conservação esteja localizada e o fator de conservação; 
$\mathbb{S} 2^{\circ}$ São variáveis de caráter qualitativo, o coeficiente de conservação da unidade de conservação e o desempenho das ações que visam garantir a melhorar a conservação da unidade de conservação, definidos a partir das respectivas Tábuas de Avaliação.

Com relação ao critério UC, os IPM-ICMS são computados tomando como base os Índices de Conservação da Biodiversidade dos Municípios (ICBM), parâmetros determinados a partir dos Coeficientes de Conservação da Biodiversidade da Unidade de Conservação (CB), de cada município, nos termos do art. $4^{\circ}$ do Decreto Estadual $n^{\circ} 25.574 / 2003$. Mas convém destacar que os procedimentos adotados para a avaliação qualitativa das Unidades de Conservação são previstos em portarias da Agência Estadual de Meio Ambiente e Recursos Hídricos de Pernambuco (CPRH) e que, durante a construção deste trabalho, não foi identificada a aritmética combinatória das avaliações qualitativas e quantitativas utilizadas para o cálculo do IPM-ICMS referente ao critério UC.

Conforme informações da Secretaria do Meio Ambiente e Sustentabilidade de Pernambuco, em 2016, o Recife contava com 27 das 81 Unidades de Conservação criadas no Estado (RECIFE, 2016), mas devido à previsão do $\mathbb{S} 2^{\circ}$, do $\operatorname{artigo} 2^{\circ}$, do Decreto Estadual $n^{\circ} 23.473 / 2001$, em 2015, a capital pernambucana foi beneficiada com apenas R \$ 570.282,54, o que corresponde a 2,26\% da quantia do ICMS Líquido relacionada ao critério UC. No tocante a este critério, o segundo município mais beneficiado, em 2015, foi Araripina, com R\$ 318.661,88, por apresentar em seu território a Área de Proteção Ambiental (APA) Federal do Araripe, que abrange 1.063.000 hectares distribuídos entre Pernambuco, Ceará e Piauí.

De acordo com as informações da Portaria Sefaz-PE n 209/2015, que apresenta os indicadores socioambientais utilizados no cálculo do IPM-ICMS, relativamente ao exercício 2016, 65 municípios pernambucanos foram beneficiados com o repasse da receita do ICMS referente ao critério Unidades de Conservação, o que equivale a $35,3 \%$ dos entes municipais. Silva Jr. et al. (2010) informam que, em 2008, foram favorecidos $26,08 \%$ dos municípios, correspondendo a um incremento de aproximadamente 9,2\% na quantidade dos entes agraciados em 8 anos neste critério ambiental.

A partir das informações analisadas, verifica-se que o critério Resíduos Sólidos, utilizado pela Lei do ICMS Socioambiental de Pernambuco para repartição de parte da receita do ICMS a que os municípios têm direito, nos exercícios de 2010 a 2017, beneficiou os entes federativos mais populosos, sem reconhecer políticas locais de resíduos sólidos, como coleta seletiva e reciclagem, critérios previstos, a partir do exercício 2018, para a repartição do produto do ICMS recolhido no Estado. Quanto ao critério Unidades de Conservação, a Lei do ICMS Socioambiental não tem compelido os entes políticos a implantarem espaços ambientalmente protegidos em virtude da reduzida quantia da receita do ICMS repassada aos municípios, pois a legislação prevê a transferência de apenas $0,25 \%$ do produto da arrecadação do ICMS aos entes municipais. 